\title{
Using the SWEPT Methodology for a Preliminary Wind Potential Estimation
}

\author{
Jean-Luc Menet ${ }^{1,2}$ \\ ${ }^{1}$ ENSIAME, Université de Valenciennes et du Hainaut, Cambrésis, 59313 Valenciennes Cedex, France \\ ${ }^{2}$ Université Lille Nord de France, 59000 Lille, France \\ Correspondence should be addressed to Jean-Luc Menet; jean-luc.menet@univ-valenciennes.fr
}

Received 12 December 2013; Accepted 22 January 2014; Published 9 March 2014

Academic Editors: S. Li and S. Rehman

Copyright (C) 2014 Jean-Luc Menet. This is an open access article distributed under the Creative Commons Attribution License, which permits unrestricted use, distribution, and reproduction in any medium, provided the original work is properly cited.

\begin{abstract}
The implantation of wind turbines generally follows a wind potential study which is made using specific numerical tools; the generated expenses are only acceptable for great projects. The purpose of the present paper is to propose a simplified methodology for the evaluation of the wind potential, following three successive steps for the determination of (i) the mean velocity, either directly or by the use of the most occurrence velocity (MOV); (ii) the velocity distribution coming from the single knowledge of the mean velocity by the use of a Rayleigh distribution and a Davenport-Harris law; (iii) an appropriate approximation of the characteristic curve of the turbine, coming from only two technical data. These last two steps allow calculating directly the electric delivered energy for the considered wind turbine. This methodology, called the SWEPT approach, can be easily implemented in a single worksheet. The results returned by the SWEPT tool are of the same order of magnitude than those given by the classical commercial tools. Moreover, everybody, even a "neophyte," can use this methodology to obtain a first estimation of the wind potential of a site considering a given wind turbine, on the basis of very few general data.
\end{abstract}

\section{Introduction}

At the end of 2010, the global capacity of wind electricity power has reached $200 \mathrm{MW}$. Consequently, the electric production was about $430 \mathrm{TWh}$, that is, $2.5 \%$ of the global electricity consumption [1]. Recent development of wind energy let us think that this general trend will continue in the next few years, and it is clear that developers have integrated this fact in their business plans.

Nowadays, wind turbine implementation is an activity which is clearly controlled. Wind farms are obviously built to produce the greatest quantity of energy on the site. However, it has been shown that the efficiency of wind turbines is not the major criteria for the use of wind turbine $[2,3]$. This fact has permitted to develop research about new concepts of wind turbines with higher energy production despites a rather low efficiency. This time is partially gone and nowadays, either for on-shore wind turbine installation or off-shore projects; the methodology is rather easy: it consists in choosing a good site (i.e., with a lot of "regular" wind) and to put on it wind machines of high nominal power and high efficiency.

The reason of these facts is clear. Wind energy production has become an industrial activity, which is now mature. Many studies have been made to attest this reality, for example, [4]. Of course, this activity is of great interest because it allows the production of green energy for reduction of climate changes, or the diminution of fossil energy uses: more simply, it is a profitable activity.

This profitability is different depending on the site. Then it is necessary to predict the delivered energy for a given project before the equipment of a place. To do that, developers generally use specific software such as Wasp [5], WindPro [6], OpenWind [7], and Retscreen [8], which traduce into clear numbers a very complex methodology. Some numerical tools are adapted to urban area [9], but whatever the software, the difficulty generally comes from the financial cost of this essential part of the study, as seen below. In fact, it has a significant financial cost while the project is not sure to succeed. The other problem is the required competence of the 
customer for the use of such software itself but also for the analysis of the results.

In fact, no wind can be correctly estimated without measurements. The height of the wind turbine must be taken into account, such as its aerodynamic and electric performances. The geographic configuration of the site around the wind turbine must be known and studied; the ground must be perfectly known in order to consider the surface roughness. The wind velocity must be measured so that the wind distribution can be correctly estimated. When it is impossible, a statistical distribution can be used, such as the Weibull distribution [10], but specific distributions exist [11]. This more complicated methodology can be followed with a certain success but it generates a financial cost which is generally only acceptable for great projects, such as wind farms of several MW installed power. For little installations, the cost per installed $\mathrm{kW}$ could be too important compared with the global cost. In case of a little installation, or for a new preproject, this part of a project can be a problem for the investor.

An alternative solution for such project is to simplify the previous methodology with the aim of obtaining an estimation of the delivered wind energy with an acceptable accuracy.

The present study presents a simplified (S) approach to estimate the wind potential of a place. This approach can be described in few steps based on three general characteristics:

(i) the wind estimation (WE) must be made; that is, the wind distribution is known;

(ii) the place (P) must be known; that is, the local geography and the roughness surface are known;

(iii) the turbine $(\mathrm{T})$ is completely defined; that is, its characteristics are known.

Let us notice that each of the previous points is in fact essential. The last one is according to us very important; however, it is regularly forgotten because in many cases the choice of the wind turbine is made before the estimation and not during the estimation.

The proposed methodology is not so different from the classical ones and is not in essence new. The real difference between the present methodology and the one used in different software is the simplification of the prediction process with the aim of a predesign project. Consequently the results will only consist in giving an "acceptable" order of magnitude to the designer or installer before using more conventional tools.

This approach is here called the SWEPT methodology. It has been recently presented, but the software was not realized and completely tested [12].

In the following, the methodology is exposed on the basis of each step of the present approach, that is, the wind estimation step (WE, coming from estimation of the wind velocity distribution), the $\mathrm{P}$ step (place configuration), and the $\mathrm{T}$ step (choice of the turbine). Preliminary results are presented and discussed. Then perspectives are given to improve the methodology.

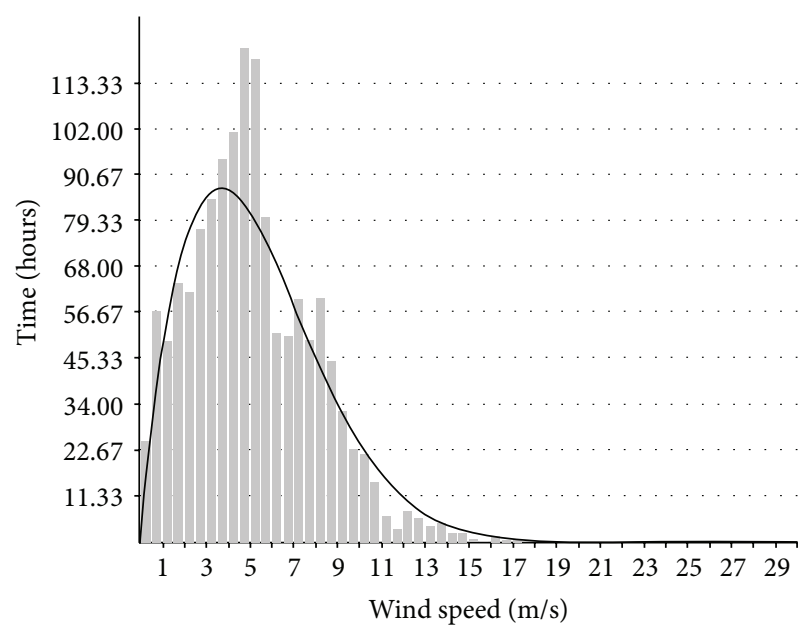

FIgURE 1: Example of Weibull modeling for $k=1.75$ and $c=5.99$ (source: http://nswep.electricalcomputerengineering.dal.ca/tools/ sv99b99e.jpg).

\section{The SWEPT Methodology}

Each step of the methodology must be carefully developed with an objective of extreme simplification.

2.1. The Wind Estimation Step (WE): Estimation of the Wind Distribution. The first step consists of the calculation of the wind distribution curve. If wind velocity measurements are available, this distribution curve can be deduced from the data using a Rayleigh distribution, which is a particular case of the two-parameter Weibull distribution, with a single parameter [13].

The probability density of the wind for a Weibull distribution, which represents the probability to obtain the velocity $V$ during a year, is given by

$$
f(V)=k \cdot c^{-k} \cdot V^{(k-1)} \cdot e^{-(V / c)^{k}},
$$

where $k$ is the form factor and $c$ is the scale parameter. These two parameters must be calculated from the real wind distribution. The aim of this paper is not to detail the different methodologies which permit to obtain a correct Weibull distribution from a velocity repartition. For additive information, see, for example, [14].

Figure 1 represents an example of a Weibull modeling. It is shown that, in some cases, the modeling is not as good as desired; however, this modeling is currently used for wind distribution models.

The mean velocity $V_{m}$ of the wind can be easily calculated using relation (1), which can be interesting because in most cases, and this quantity is known or can be known. Consequently, the scale factor can be written as follows:

$$
c=\frac{V_{m}}{\Gamma(1+(1 / c))},
$$

where $\Gamma$ is the gamma function here applied to the quantity $1+(1 / c)$. 
TABLE 1: On-shore Beaufort scale.

\begin{tabular}{lccl}
\hline $\begin{array}{l}\text { Beaufort } \\
\text { number }\end{array}$ & $\begin{array}{c}\text { Estimated } \\
\text { Velocity }(\mathrm{m} / \mathrm{s})\end{array}$ & $\begin{array}{c}\text { International } \\
\text { description }\end{array}$ & Observed conditions \\
\hline 0 & $<1$ & Calm & $\begin{array}{l}\text { Smoke rises vertically } \\
\text { Direction of wind shown by smoke drift but not by wind } \\
\text { vanes } \\
1\end{array}$ \\
1 & 2 & Light air & Wind felt on face: leaves rustle, vanes move by wind \\
2 & 4 & Gentle breeze & $\begin{array}{l}\text { Leaves and small twigs in constant motion; wind extends } \\
\text { light flag }\end{array}$ \\
3 & 7 & Moderate & $\begin{array}{l}\text { Raises duct, loose paper; small branches move } \\
\text { Small trees in leaf begin to sway; crested wavelets form on }\end{array}$ \\
4 & 10 & Fresh & inland waters \\
5 & 12 & Strong & $\begin{array}{l}\text { Large branches in motion; whistling heard in telephone } \\
\text { wires; umbrellas used with difficulty }\end{array}$ \\
6 & 15 & Near gale & Whole trees in motion; resistance felt walking against wind \\
7 & 18 & Gale & Breaks, twigs off trees; impedes walking \\
8 & 20 & Strong gale & Slight structural damages occurs \\
9 & 26 & Trees uprooted; considerable damage \\
10 & 30 & Violent storm & Widespread damage \\
\hline 11 & & &
\end{tabular}

In the Rayleigh distribution, $k$ is said to be equal to 2.0, so that $\Gamma=\sqrt{\pi} / 2$. Then the problem is greatly simplified and corresponds to a good approximation of most wind sites. The Rayleigh distribution has another advantage: if measured data of wind distribution are not available, the single knowledge of the mean velocity $V_{m}$ is sufficient for the determination of the Rayleigh distribution according to relation (3):

$$
f(V)=\Delta V \cdot \frac{\pi}{2} \cdot \frac{V}{V_{m}^{2}} \cdot e^{-(\pi / 4)\left(V / V_{m}\right)^{2}} .
$$

For a given gap $\Delta V$ of the wind velocity, the probability density is calculated, which means that the whole wind distribution is approximated directly from the quantity $V_{m}$. However, in some cases, the mean velocity $V_{m}$ is not available because it usually supposes that at least 18 months of measurements have been done on the place where a wind turbine is to be installed. In this case, an alternative is to estimate this quantity $V_{m}$ if it is known at a place not far from the chosen site. This strategy is dangerous because each site is particular, but from a preliminary approach, it is generally impossible to use another method.

In the present paper, a third approach is given. We propose to use a subjective data: the most occurrence velocity (MOV). This method consists in an estimation of the MOV, using a scale derived of the Beaufort scale for example. Table 1 represents a transposition of the wind velocity from subjective elements. Of course, most of the wind sites have a Beaufort number inferior to 6 .

For a Rayleigh distribution, the mean velocity $V_{m}$ can be easily expressed from the MOV according to the following equation:

$$
V_{m}=\frac{\operatorname{MOV} \cdot \sqrt{2 \pi}}{2}
$$

Figure 2 gives an example of a Rayleigh distribution for a year, built either from the mean velocity $V_{m}$ or the MOV. Let us notice that the MOV corresponds to the maximum of the velocity distribution, that is, the highest number of hours corresponding to a given wind velocity.

Using this method, it is possible to estimate not only the mean velocity $V_{m}$ but also the whole wind distribution as seen above. This method can be put in a simple numerical worksheet and consequently it can be integrated in the SWEPT software.

2.2. The Place Step (P): Place Configuration. In fact, the velocity distribution described in part 2.1 must be adapted because of the supposed height of the wind turbine. Numerous authors propose empirical law to estimate the wind velocity at different heights (see, e.g., [15]). In the present study, we chose to use a more conventional way: a classical power law is proposed and is directly related to the previous height $h$ (Davenport and Harris law). This type of power law is not recent at all (see, e.g., [16]) but is currently used to predict velocities in "conventional" areas. Let us consider that this method is obviously an approximation and only precise measurements can give a good idea of the winds on a given site. As seen above, the present methodology aims to give an "acceptable" order of magnitude to the designer or installer.

The wind velocity $V_{T}$ at the height $h_{T}$ is given by the following relation:

$$
\frac{V_{T}}{V}=\left(\frac{h_{T}}{h}\right)^{\alpha}
$$

where $h_{T}$ is the height where the main rotor shaft of the turbine is located, and where $h$ is the height where the velocity is supposed to be measured or known: $V$.

The common value of the parameter $\alpha$ is often taken to be equal to 1/7 (fully developed turbulent atmospheric boundary 
layer). Then, the wind distribution can be estimated at the height $h_{T}$ of the main rotor shaft. Of course, the value of $\alpha$ depends on the configuration of the ground, namely, the roughness. Generally, it is estimated by the software (see, e.g., [5]). Other engineers directly use internet free information, for example, given by google-maps (Inc.) [17]. In fact, the simple knowledge of the ground typology (e.g., ice, grass, etc.) is more than sufficient for a first approach and gives generally better results than the two previous methods. This consists in giving another value to the parameter $\alpha$ in (5) according to Table 2 [18].

All these calculations lead to the estimated wind distribution at the wanted height $h_{T}$ of the wind turbine. Let us consider that only the "subjective knowledge" of the wind (value of the MOV) and the height of the main rotor shaft are necessary for that. This step is in fact very easy to put in a numerical worksheet and to implement in specific software.

Let us notice that the surrounded wind configuration coming from the wind rose is not considered here.

2.3. The Turbine Step (T): Choice of the Turbine. As seen above, wind turbines are generally chosen before the calculation of the delivered energy and are not directly included in the methodology. This seems to be very strange because many parameters are "interconnected" for the calculation. For example, the previous step supposes that the height of the turbine is known, but the chosen height also depends on the considered power, while the turbine is not yet chosen.

In fact, installers have generally an idea of the rotor and they "just" use the electrical curve (electric power versus wind velocity) to calculate the energy production from the velocity distribution on a given site.

Commercial software proposes many wind turbines to be "tried" directly in the modeling. But this methodology is time dependant. Besides, these data are not systematically available, especially for micro- and small turbines installation on "unknown sites." The present methodology aims to use a simplified definition of the turbine.

Let us consider that a wind turbine is in fact essentially given by two data (see Figure 3):

(i) the starting point is the one where the wind turbines runs on; that is, there is no power under the velocity $V_{d}$;

(ii) the nominal point corresponds to the generated power $P_{n}$ for the velocity $V_{n}$.

After the nominal point, the curve is around a horizontal line. Sometimes, a third point is given: the "breaking point" where the velocity is so high that the wind turbine must be stopped. But this third point is situated for high velocity values which are very rare, so that the corresponding energy during a year is very small. Under these considerations, the power curve of the wind turbine can easily be approximated by two lines (in blue in Figure 3), which makes it easier to calculate the electricity production in regards of the distribution curve (Figure 2): for each value of the velocity, the number of "hours of wind" and the delivered power are known, and the energy
TABLE 2: Estimation of the velocity from the ground roughness knowledge.

\begin{tabular}{lc}
\hline Ground type & $\alpha$ \\
\hline Ice & 0.07 \\
Snow on a flat ground & 0.09 \\
Calm sea & 0.09 \\
Short cut grass & 0.14 \\
Meadow & 0.16 \\
Cereal cultures & 0.19 \\
Hurdles & 0.21 \\
Trees and scattered hurdles & 0.24 \\
Trees and dense hurdles & 0.29 \\
Suburban or urban site & 0.31 \\
Forest & 0.43 \\
\hline
\end{tabular}

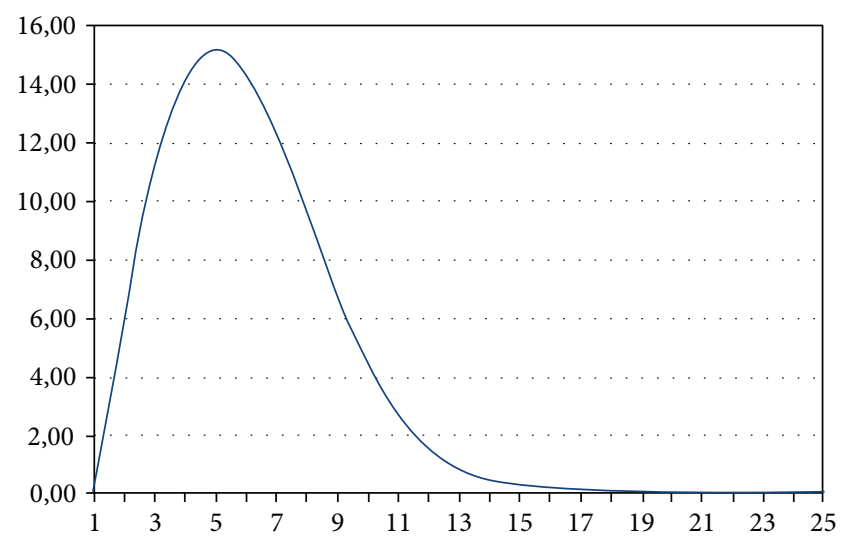

FIGURE 2: Rayleigh distribution (\%) for a given value of $V_{m}$ or MOV.

is just the product of the power by the number of hours at this power.

This step is in fact very easy to put in a simple numerical worksheet. Let us notice that the present methodology will probably overestimates the wind potential in a way that should be clarified. In fact, it is possible to propose other curves than a simple line to estimate the power curve between the $V_{d}$ and $V_{n}$ values, which should limit part of the problem.

\section{The SWEPT Software}

The proposed software can be a single numerical worksheet and the user has just to answer several questions which are easy to understand.

First the user must put the mean velocity at a height of $10 \mathrm{~m}$, because this data is currently known. If this quantity is not known, it is possible to put the value of the MOV variable, or to choose a mean value coming from a standard wind atlas (see, e.g., [19]), according to Figure 4. Obviously, the more correct the value of $V_{m}$ is, the more precise the calculation will be.

Then the estimated height $h_{T}$ of the wind turbine is asked, such as the value of the parameter $\alpha$ given in relation (4). The user is guided in the choice of $\alpha$ by the use of Table 2 . 


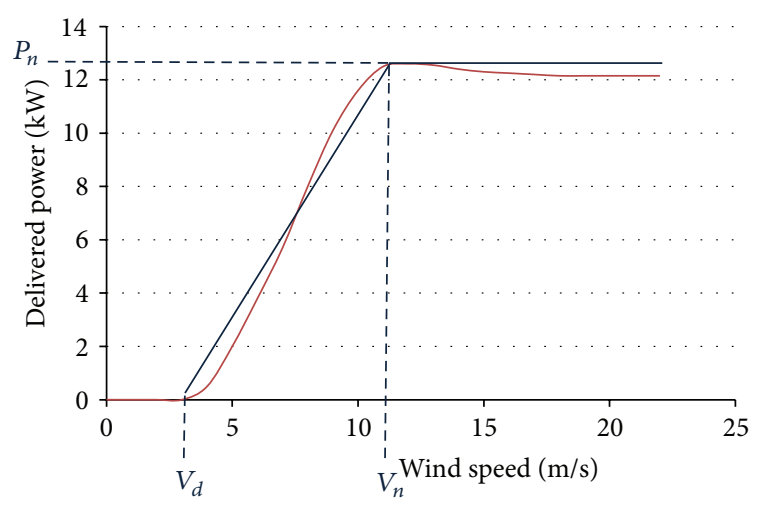

FIGURE 3: Example of a power curve for a given wind turbine.

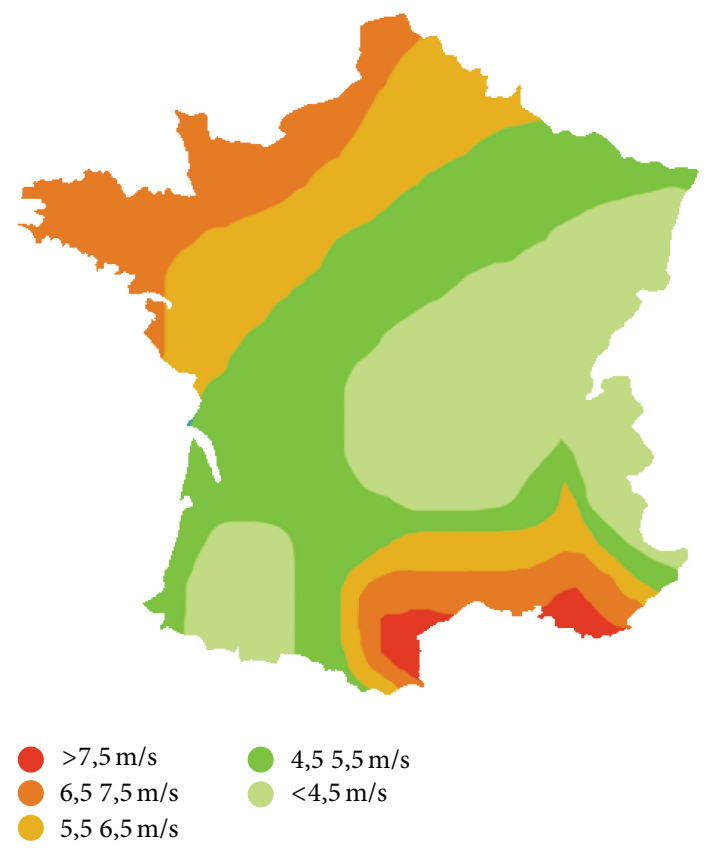

Figure 4: Estimated mean velocity range at $10 \mathrm{~m}$ high (in France) (source: http://upload.maieutapedia.org/picture/carte_des_vents_ (2)1282816063.png).

TABLE 3: Main characteristics of the chosen wind turbine: Enercon 33-49.

\begin{tabular}{lc}
\hline Nominal power $(\mathrm{kW})$ & 330 \\
Height of the shaft $(\mathrm{m})$ & 49 \\
Rotor diameter $(\mathrm{m})$ & 33.4 \\
$V_{d}(\mathrm{~m} / \mathrm{s})$ & 3 \\
$V_{n}(\mathrm{~m} / \mathrm{s})$ & 13 \\
\hline
\end{tabular}

The two previous steps permit to plot the wind distribution according to relations (3) and (5), so that a Rayleigh distribution is proposed as the one shown in Figure 2.

Finally, the user must enter the three values $V_{d}, V_{n}$, $P_{n}$ which approximate the characteristic curve of the wind turbine and the software simply returns the value of the
TABLE 4: Comparisons of the annual delivered energy for the Enercon 33-49 turbine (kWh) on a given place located on a calm sea (France).

\begin{tabular}{lc}
\hline Use of the software (8) & Present study: SWEPT methodology \\
\hline $370 \mathrm{MWh}$ & $385 \mathrm{MWh}$ \\
\hline
\end{tabular}

delivered energy for a year. Let us notice that the software could estimate the profitability of the project, but this step has not been performed yet. Figure 5 describes in a full organization chart the methodology which is used in the worksheet.

\section{Results and Discussion}

The software has been realized following the SWEPT methodology; it has been first developed in a single worksheet and then was implemented in a specific numerical tool, easy to use by everybody. Figure 6 is a single capture of the screen to let the reader have an idea of it.

The software has been tested for a few standard wind turbines. The results returned by the "calculator" have been compared to few commercial tools. In the present study, we just present the results for a typical wind machine, the characteristics of which are known: Enercon 33-49 [20], with a $49 \mathrm{~m}$ mast, located near Lille (France). Main properties of this machine can be found in Table 3. Figure 7 shows the power curve of the turbine given by the constructor or calculated using the SWEPT methodology.

The results coming from the SWEPT software have been compared to the ones given by the software [8]. The delivered energy for a year has been said to be equal to $385 \mathrm{MWh}$ (SWEPT) and to $370 \mathrm{MWh}$ [8], which corresponds to a good agreement (Table 4). Other calculations have been made for small and microturbines (more adapted to urban area) and show that the difference is always inferior to $20 \%$ whatever the case is [21]. Of course, all the parameters (such as the Rayleigh accuracy or the good agreement of the parameter $\alpha$ ) have not been tested yet because the first idea was to estimate the pertinence of such a simple software. Additive comparisons can be obtained from the author [21, 22].

Let us notice that the differences between the results were expected because some uncertainties have been made, but on the other hand, the commercial tools themselves can introduce some differences with the reality.

In fact, the real interest of the SWEPT methodology and of the corresponding software (which can be a single worksheet) is not the reduction of the uncertainty, but

(i) the simplicity of use;

(ii) the remarkable time of "calculation" (corresponding to the filling of the worksheet and the results).

Considering the 2 nd point, only few seconds are necessary to achieve the "calculation." 


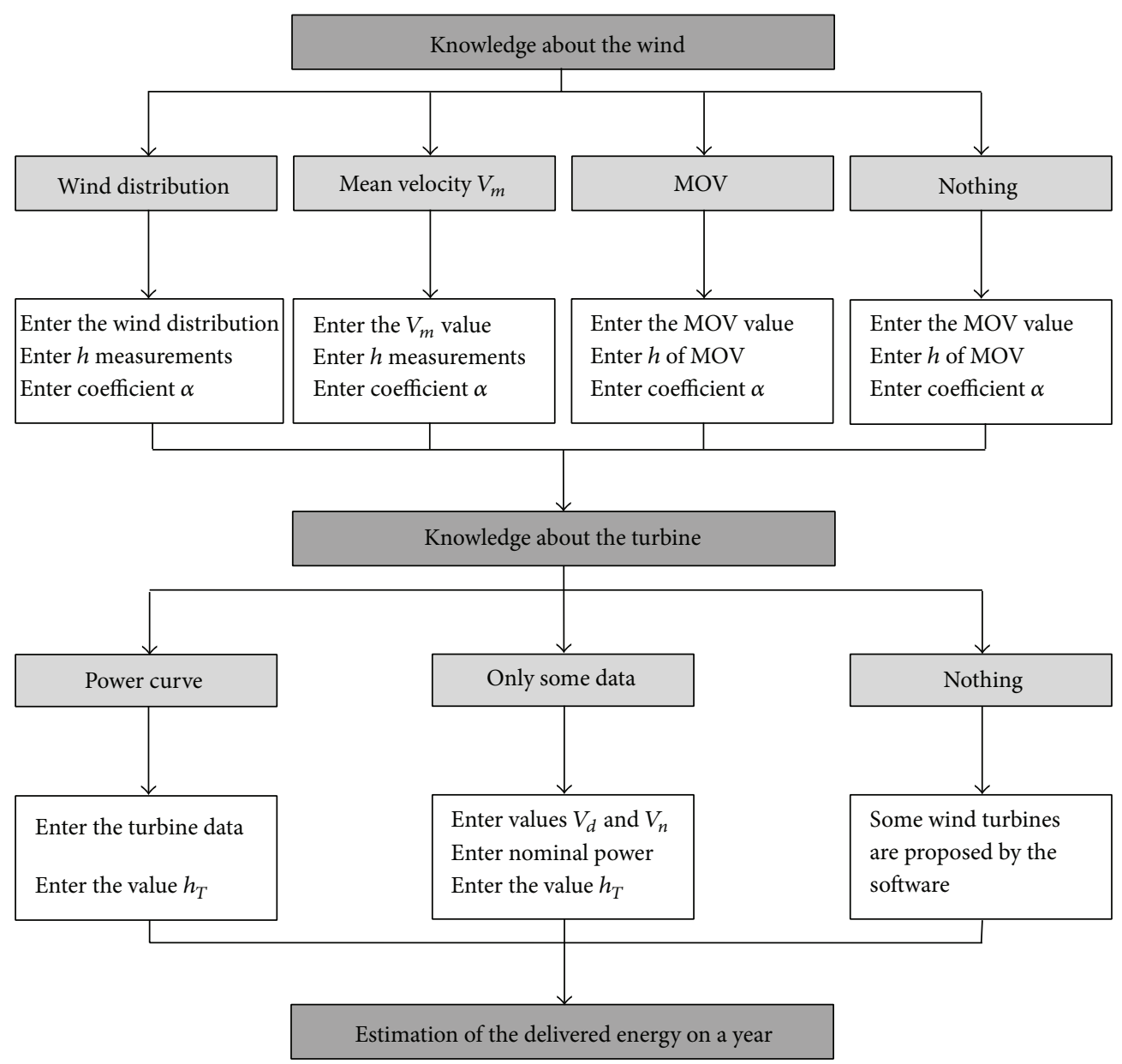

FIGURE 5: SWEPT organization chart.

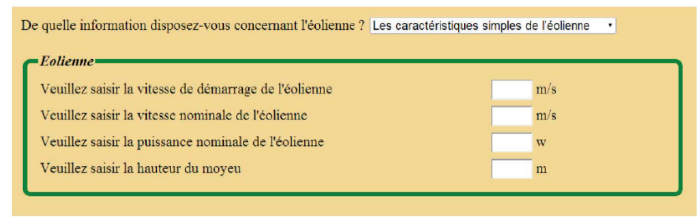

(a)

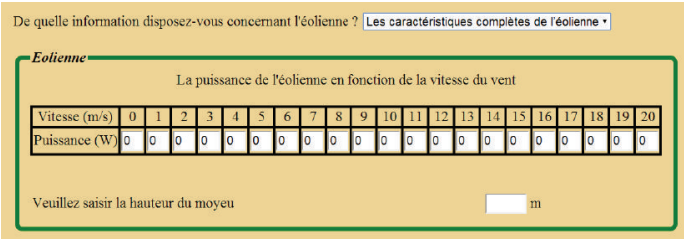

(b)

FiguRE 6: Some questions proposed to the user by the software (in French).

\section{Conclusion and Perspectives}

The proposed methodology permits a "neophyte" to predict in few seconds an estimation of the electric energy production for a wind turbine on a site. The idea is to use very few data to obtain a first order of magnitude of the estimated delivered energy. This approach has been called the "SWEPT methodology." A specific tool has been developed to estimate the wind potential. This tool, based on very simplified hypotheses, is very easy to use. An appropriate knowledge of the geography and of the velocity (mean velocity or MOV) on the site is necessary, which is probably a condition of acceptability if the local population is concerted. We have shown that the difference between the results returned using the SWEPT tool and the ones given by different commercial software do not exceed $20 \%$ in most cases. This is in good agreement with the main objective of present study: to give quickly an acceptable estimation of the delivered energy of a wind turbine. In a following step of the study, the power curve is to be approached by another curve that two lines 


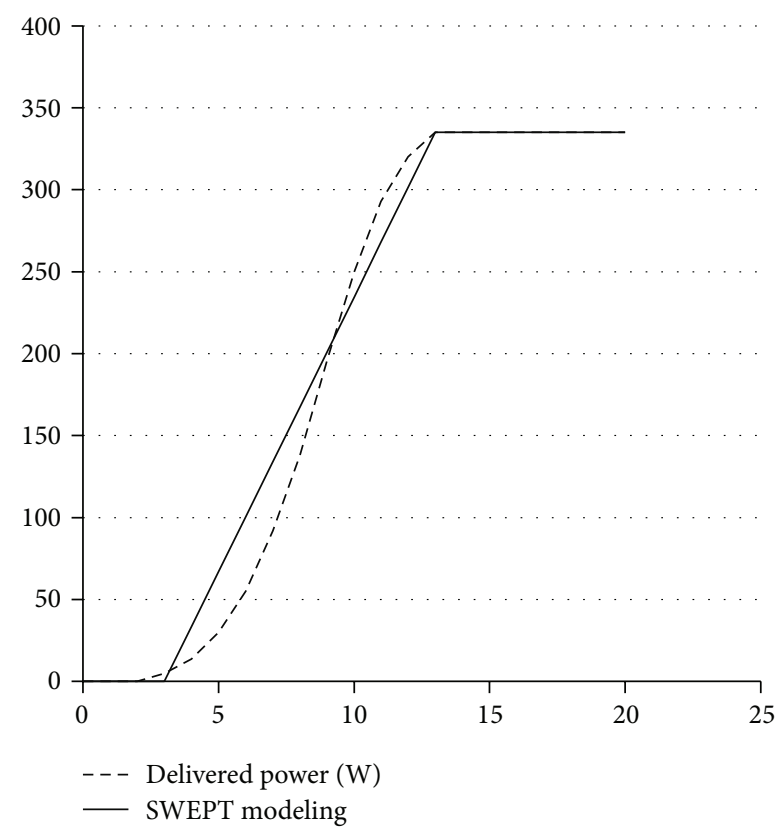

FIgURE 7: Power curve for the chosen wind turbine (Enercon 3349).

and the "subjective" knowledge of the wind will be verified by more case studies. Finally, a profitability calculation will be proposed.

\section{Conflict of Interests}

The author declares that there is no conflict of interests regarding the publication of this paper.

\section{References}

[1] World Wind Energy Association, "World wind energy report 2010," Tech. Rep., 2011.

[2] J. L. Menet and B. Ménert, "Une procédure de comparaison de quelques éoliennes classiques basées sur l'utilisation du critère L-sigma," in Proceedings of the 15è Congrès Français de Mécanique, Grenoble, France, 2001.

[3] J. L. Menet, L. C. Valdès, and B. Ménart, "A comparative calculation of the wind turbines capacities on the basis of the $L-\sigma$ scriterion," Renewable Energy, vol. 22, no. 4, pp. 491-506, 2001.

[4] European Wind Energy Association, "Pure power, wind energy targets for 2020 and 2030," Tech. Rep., 2009.

[5] http://www.wasp.dk.

[6] http://www.emd.dk.

[7] http://www.awsopenwind.org.

[8] http://www.retscreen.net/.

[9] http://www.meteodyn.com.

[10] J. V. Seguro and T. W. Lambert, "Modern estimation of the parameters of the Weibull wind speed distribution for wind energy analysis," Journal of Wind Engineering and Industrial Aerodynamics, vol. 85, no. 1, pp. 75-84, 2000.
[11] A. N. Celik, "A statistical analysis of wind power density based on the Weibull and Rayleigh models at the southern region of Turkey," Renewable Energy, vol. 29, no. 4, pp. 593-604, 2004.

[12] J. -L. Menet, "A simplified approach for teh evaluation of the wind potential: the SWEPT methodology," in Proceedings of the 21st French Mechanical Conference (CFM '13), Bordeaux, France, 2013.

[13] M. T. Alodat and Y. N. Anagreh, "Durations distribution of Rayleigh process with application to wind turbines," Journal of Wind Engineering and Industrial Aerodynamics, vol. 99, no. 5, pp. 651-657, 2011.

[14] C. G. Justus, W. R. Hargraves, A. Mikhail, and D. Graber, "Methods for estimating wind speed frequency distributions," Journal of Applied Meteorology, vol. 17, no. 3, pp. 350-353, 1978.

[15] S. Rehman, L. M. Al-Hadhrami, M. Alam, and J. P. Meyer, "Empirical correlation between hub height and local wind shear exponent for different sizes of wind turbines," Sustainable Energy Technologies and Assessment, vol. 4, pp. 45-51, 2013.

[16] A. G. Davenport, "The spectrum of horizontal gustiness near the ground in high winds," Quarterly Journal of the Royal Meteorological Society, vol. 87, no. 372, pp. 194-211, 1961.

[17] Google Maps, https://maps.google.fr.

[18] S. Cullen, "Trees and wind: wind scales and speeds," Journal of Arboriculture, vol. 28, no. 5, pp. 237-242, 2002.

[19] http://eolienne.f4jr.org/pays/france.

[20] http://www.enercon.de/p/downloads/EN_la_gamme.pdf.

[21] A. Girard, D. Kubalcki, J. Lemoine, M. A. Niang, and R. Toahi, "Réalisation d'un outil de calcul du productible éolien: EOLBAT," Projet Report, ENSIAME, study supervised by J-Luc Menet, 2012.

[22] B. Denisse and J. Giguere, "Conception d'un outil ALL pour la détermination du captable et du productible éolien," Projet Report, ENSIAME, study supervised by J-Luc Menet, 2011. 


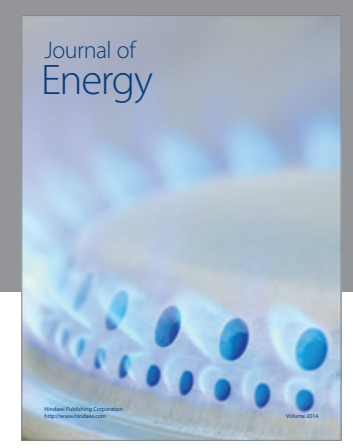

Journal of

Industrial Engineering
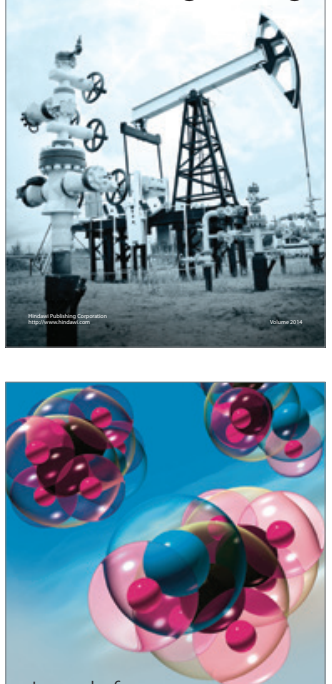

Fuels
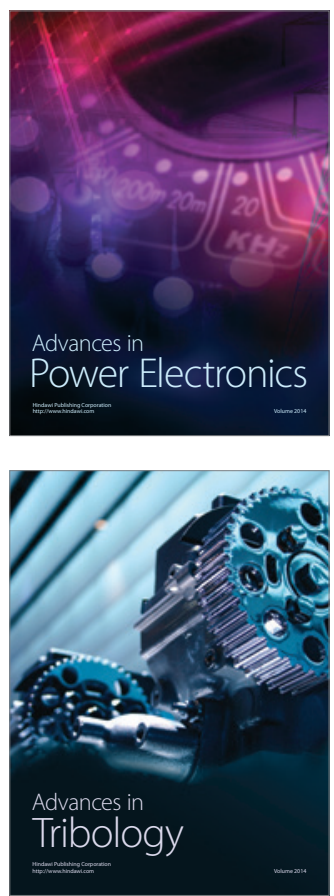

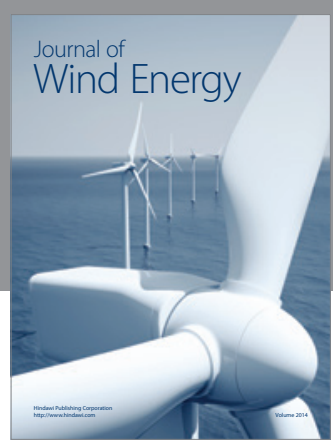

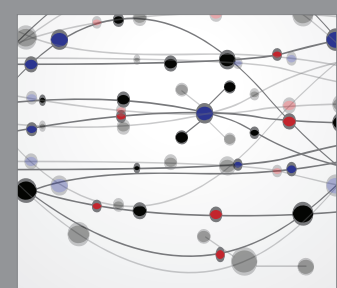

The Scientific World Journal

Submit your manuscripts at http://www.hindawi.com

Journal of

Structures
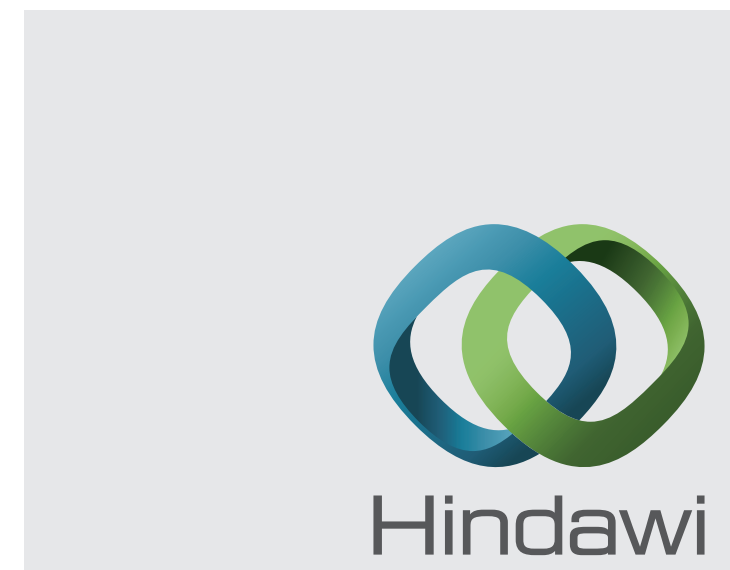

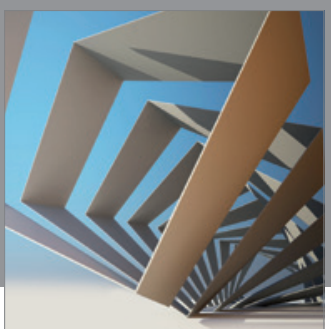

Rotating

Machinery
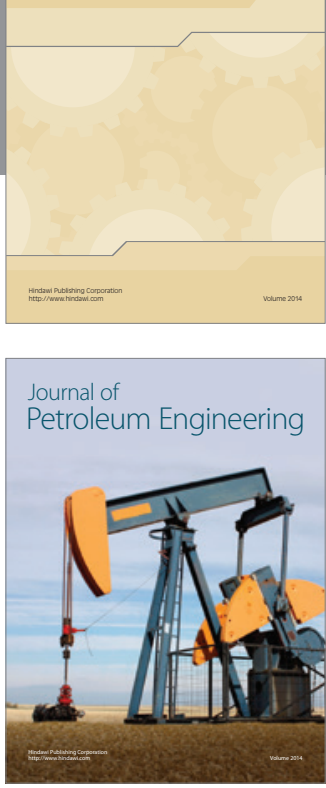

Journal of

Solar Energy
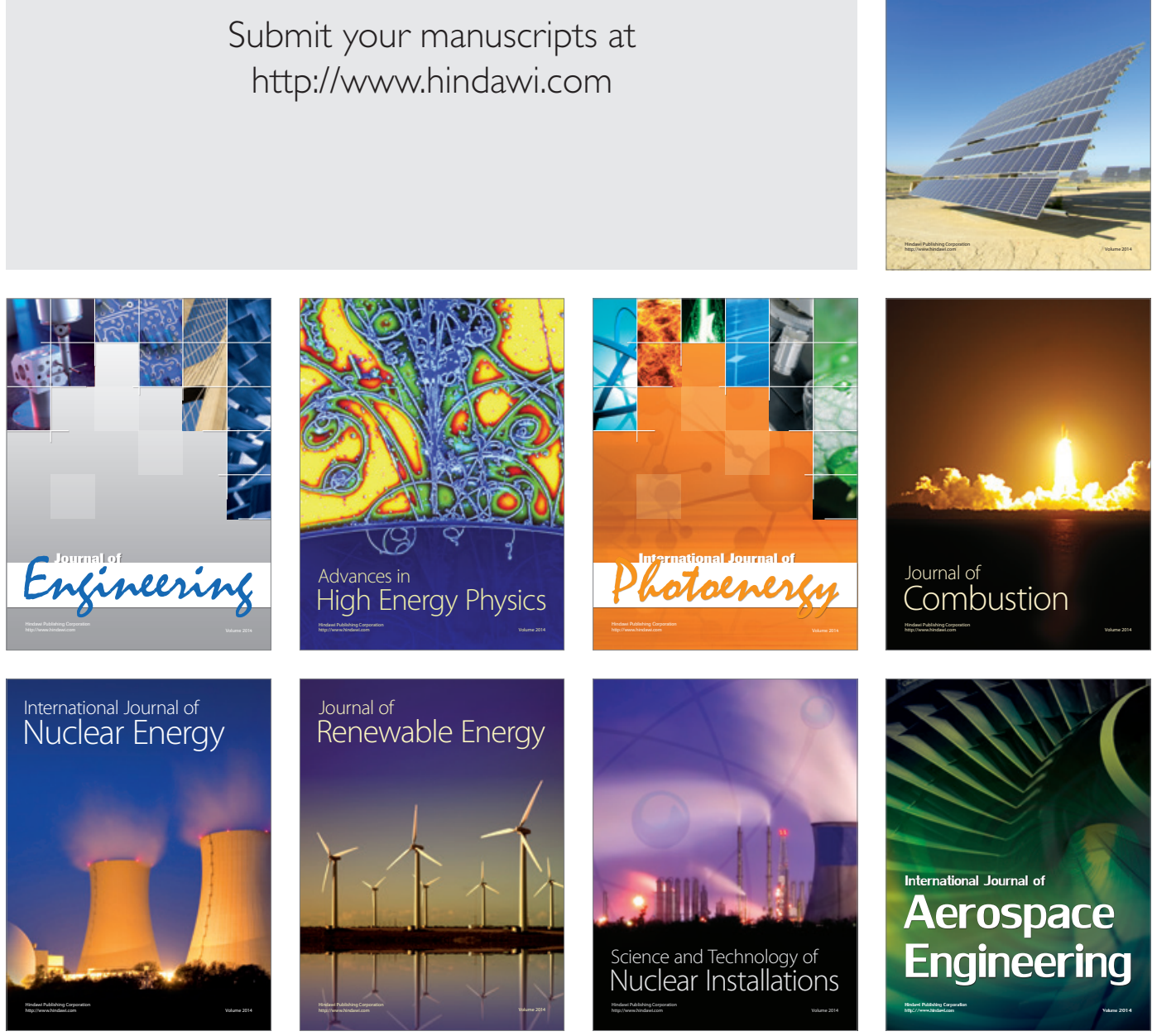